\title{
Abdelhamid H Elgazzar, Saud Alenezi (Eds). A concise guide to nuclear medicine. Second Edition
}

\author{
Springer Nature Switzerland AG 2020. ISBN 978-3-030-26064-4
}

\author{
Luigi Mansi ${ }^{1}$ \\ Published online: 13 January 2021 \\ (C) The Author(s), under exclusive licence to Springer-Verlag GmbH, DE part of Springer Nature 2021
}

Abdelhamid H Elgazzar is Professor and Chairman of the Department of Nuclear Medicine at the Kuwait University. He edited this book together with Saud Alenezi, Assistant Professor at the same Institution.

Elgazzar's name is for me a guarantee of quality and interest for a publication on nuclear medicine. Whether he's editing a large book or a concise guide like this one, his style is recognizable. He is a publisher who takes a great care of the general format and of the individual chapters, creating a homogeneous editorial product, even when the contributions are not written by him. In particular, I appreciate in his publications the clear reference to physiopathology, which is the true soul of nuclear medicine.

This book, extensively revised in this second edition, coming 9 years after the first one, is an agile publication of 159 pages with very clear images and schemes and a Glossary at the end. It is organized in the following 11 chapters: (1) Basic Principles of Nuclear Medicine; (2) Nuclear Medicine in the Genitourinary System; (3) Nuclear Medicine in the Digestive System; (4) Nuclear Medicine in the Endocrine System; (5) Nuclear Medicine in Soft-Tissue Infection and Inflammation; (6) Nuclear Medicine in the Respiratory System; (7) Nuclear Medicine in the Musculoskeletal System; (8) Nuclear Medicine in the Cardiovascular System; (9) Nuclear Medicine in the Nervous System; (10) Nuclear Medicine in Oncology; (11) Therapeutic Applications of Nuclear Medicine.

Luigi Mansi

mansi.luigi@libero.it

1 Section Health and Development, Interuniversity Research Center for Sustainability (CIRPS), Naples, Italy
The didactic style of the clinical chapters is structured with an introduction, the clinical questions and applications, the most frequent but also less diffuse techniques and procedures, a summary, and a final connection with further readings. Updated giving ample space to hybrid machines and new therapeutic applications, the book compare radionuclide methods with radiological ones, defining their primary or integrative role in the clinical scenario.

This concise guide is an introductory book to nuclear medicine, giving an easy and quick information on all the most important clinical applications without going into technical details. Primarily written for medical students, it can be very useful for referring physicians, who can better understand clinical indications. It can be also helpful for many others, including residents in other disciplines, practitioners, technologists, and nurses who want to be introduced to Nuclear Medicine.

In accordance with the intentions of prof. Elgazzar, I want to dedicate my review to the memory of the late Prof. Henry Wagner, who wrote the forewords of the first edition. This concise guide is in line with the great lesson and the extraordinary contributions that our Friend Henry has left us all.

Publisher's note Springer Nature remains neutral with regard to jurisdictional claims in published maps and institutional affiliations. 